\title{
PENGARUH KEMISKINAN, PENGANGGURAN, PERTUMBUHAN EKONOMI, DAN BELANJA MODAL TERHADAP IPM DI KABUPATEN NGANJUK TAHUN 2010-2019
}

\section{Andhita Astriani, Muchtolifah, Sishadiyati}

Universitas Pembangunan Nasional (UPN) Veteran Jawa Timur, Indonesia

Email: andhitaas@gmail.com, muchtolifah@yahoo.co.id,

Sishadiyati.ep@upnjatim.ac.id

\begin{abstract}
Abstrak
Pembangunan yaitu termasuk dalam alat yang digunakan sebagai meraih kesuksesan dalam membangun bangsa. Pembangunan manusia dapat diketahui dari tingkat kualitas hidup manusia yang ada disuatu daerah dengan ukuran yang bisa dilihat dari indeks pembangunan manusia. Tujuan dari diadakannya penelitian ini yaitu untuk menguji pengaruh antara Kemiskinan, Pengangguran, Pertumbuhan Ekonomi, Dan Belanja Modal Berpengaruh Terhadap Indeks Pembangunan Manusia Di Kabupaten Nganjuk tahun 2010-2019. Metode yang digunakan dalam penelitian ini yaitu metode kuantitatif dengan Sampel yang digunakan dalam penelitian ini yaitu Kabupaten Nganjuk pada tahun 2010-2019. Data penelitian yang digunakan yaitu data sekunder yang diambil dari Badan Pusat Statistik Provinsi Jawa Timur dan Direktorat Jendral Perimbangan Keuangan. Berdasarkan hasil pengujian, dapat disimpulkan bahwa: 1) Kemiskinan berpengaruh negatif dan signifikan terhadap IPM. 2) Pengangguran tidak berpengaruh signifikan terhadap IPM. 3) Pertumbuhan Ekonomi tidak berpengaruh signifikan terhadap IPM. 4) Belanja Modal tidak berpengaruh signifikan terhadap IPM.
\end{abstract}

Kata Kunci: kemiskinan; pengangguran; pertumbuhan ekonomi; belanja modal; IPM

\section{Abstract}

Development is included in the tools used to achieve success in building the nation. Human development can be seen from the level of quality of human life in an area with a size that can be seen from the human development index. The purpose of this research is to test the influence between Youth, Youth, Economy, and Clear Capital Expenditure Human Development Index in Nganjuk District in 2010-2019. Which method in this study quantitative method with samples in this study is Nganjuk Regency in 2010-2019. Research data which data at that time data from the Central Bureau of Statistics East Java Province and directorate general of financial balance. In the result of the creation, it is concluded that: 1) Districts are high and flat against IPM. 2) No government is not beber against IPM. 3) Economy Is Not High On IMP. 4) Capital Expenditure is not good timing outside the HDI.

Keywords: poverty; unemployment; economic growth; capital expenditure; IPM

$\begin{array}{ll}\text { How to cite: } & \text { Astriani,Andhita, Muchtolifah, Sishadiyati (2021) Pengaruh Kemiskinan, Pengangguran, } \\ & \text { Pertumbuhan Ekonomi, dan Belanja Modal Terhadap Indeks Pembangunan Manusia Di Kabupaten } \\ & \text { Nganjuk Tahun 2010-2019, Syntax Idea, 3(7). https:// doi.org/10.36418/syntax-idea.v3i7.1331 } \\ \text { E-ISSN: } & \text { 2684-883X } \\ \text { Published by: } & \text { Ridwan Institute }\end{array}$




\section{Pendahuluan}

Salah satu alat yaitu pembangunan untuk mencapai tujuan yang di inginkan suatu bangsa dan negara. Pertumbuhan ekonomi merupakan indikator untuk melihat keberhasilan pembangunan disuatu negara sehingga menjadi sasaran utama untuk bagi Negara-negara berkembang dalam melakukan pembangunan (Zakaria, 2018). Pertumbuhan ekonomi bisa diukur melalui pembangunan manusia yang dilihat dari tingkat kualitas hidup setiap manusia. ada beberapa tolak ukur yang digunakan dalam dalam melihat kualitas hidup manusia yaitu indeks pembangunan manusia yang bisa di ukur dari kualitas pelayanan kesehatan, tingkat pendidikan serta ekonomi. Adanya keberagaman individu, letak geografis dan kondisi social masyarat yang tidak sama sehingga adanya penyebab tingkat pendapatan tidak lagi menjadi tolak ukur utama dalam keberhasilan pembangunan di suatu negara (Denni Sulistio Mirza, 2012).

Kemiskinan yaitu pendapatan tiap individu pertahun tidak bisa memenuhi kebutuhan yang bersifat pokok atau pun wajib sehingga dapat digolongkan sebagai masyarakat miskin yang hidup tidak layak atau dibawah standard hidup. Kemiskinan merupakan faktor penghambat pembangunan nasional di suatu Negara. Dengan naiknya penduduk miskin di suatu Negara bahwa pemerintah belum secara maksimal meningkatkan kualitas sumber daya manusia agar terciptanya kemakmuran Pengangguran terbuka yaitu angkatan kerja yang tidak bekerja atau sedang mencari pekerjaan yang sesuai dengan skill dan pengetahuan yang dimiliki tiap individu.Tingkat pengangguran bisa dilihat dari persentase jumlah pengangguran terbuka terhadap jumlah angkatan kerja sehingga tingkat pengangguran ini bisa mempengaruhi nilai IPM di suatu daerah (Bappeda, 2020a).

Pertumbuhan ekonomi adalah tolak ukur yang bisa dipakai untuk meningkatkan pembangunan suatu daerah dari beberapa macam sektor ekonomi sehingga semakin banyak barang dan jasa yang diproduksi oleh produsen maka kesejahteraan akan meningkat dan kualitas sumber daya manusia ikut meningkat pula (Bappeda, 2020b).

Besarnya Belanja Modal pemerintah daerah selama ini sangat ditentukan oleh faktor Dana Alokasi Umum. Hasil ini mendukung penelitian terdahulu yang dilakukan oleh (Prakosa, 2004), dan hal ini juga dikemukakan oleh (Adi, 2006) yang menyatakan bahwa Dana Alokasi Umum berpengaruh signifikan terhadap Belanja Modal.

Pemerintah melakukan suatu usaha untuk meningkatkan kualitas hidup masyarakat agar semakin baik lagi kedepannya dan pemerintah membuat kebijakan dengan mengalokasikan sebagian dana yang ada dalam bentuk belanja modal. Sehingga belanja modal dapat membantu untuk meningkatkan kesejahteraan bagi masyarakat sekitar yang memerlukan pelayanan publik yang lebih baik. Berikut merupakan perkembangan Nilai IPM di Kabupaten Nganjuk Tahun 2010-2019. 
Pengaruh kemiskinan, pengangguran, pertumbuhan ekonomi, dan belanja modal

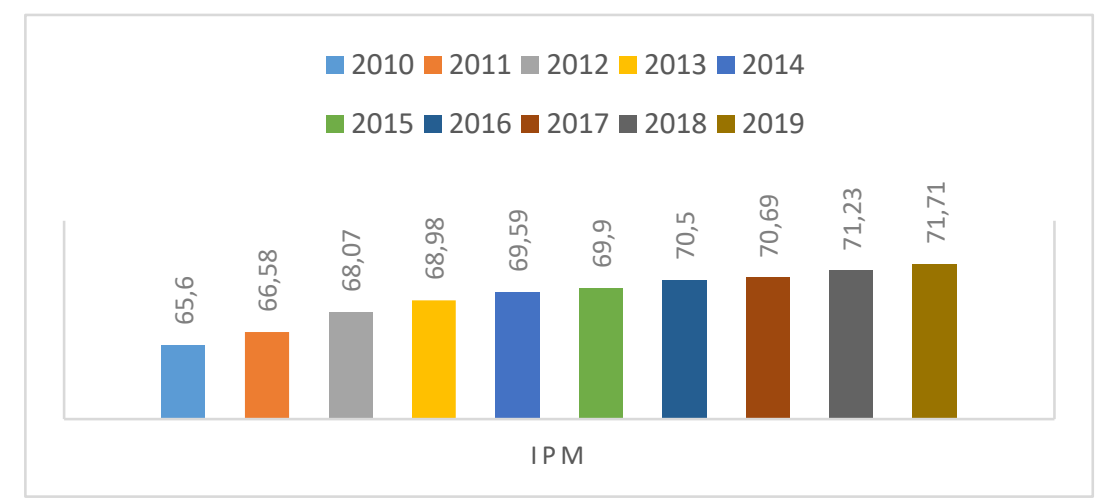

\section{Grafik 1}

Nilai IPM di Kabupaten Nganjuk Tahun 2010-2019

Sumber:Badan Pusat Statistik Nganjuk, 2020

Perkembangan pembangunan manusia di Kabupaten Nganjuk terus mengalami peningkatan setiap tahunnya. Pencapaian IPM yang akan terus meningkatidari tahun ke tahun ini, menjadi tanda bahwa kualitas pembangunan manusia di Kabupaten Nganjuk yang bisa dilihat dari beberapa aspek yaitu kesehatan, pendidikan, serta ekonomi juga semakin membaik. Untuk Indeks Pembangunan manusia di Kabupaten Nganjuk terus mengalami kemajuan.

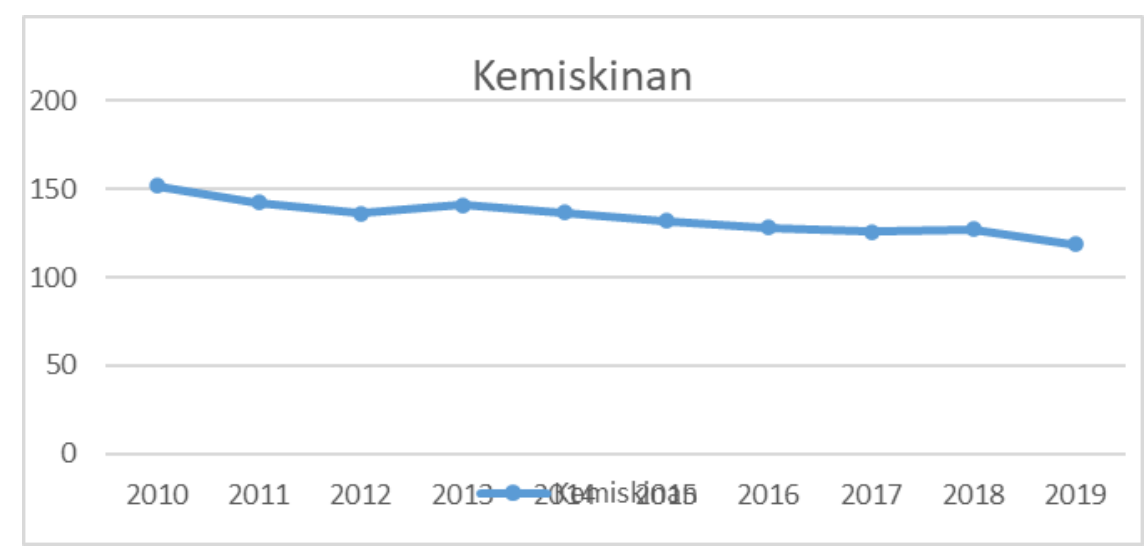

Grafik 2

Kemiskinan di Kabupaten Nganjuk Tahun 2010-2019

Sumber: Badan Pusat Statistik Nganjuk, 2020

Kemiskinan di Kabupaten Nganjuk menurut data Badan Pusat Statistik (BPS) Nganjuk dari tahun ke tahun mengalami penurunan cukup signifikan, pada tahun 2012 menurun sebesar 136.1. Hasil perhitungan ini menggunakan konsep kemampuan kebutuhan dasar, untuk melalui pendekatan kemiskinan dilihat dari ketidak mampuan sesorang di sisi ekonomi untuk memenuhi kebutuhan dasar makanan. Dengan demikian, Kabupaten Nganjuk pada tingkat kemiskinan mengalami penurunan setiap tahunnya. 
Berdasakan uraian tersebut maka rumusan masalah yang digunakan dalam penelitian ini yaitu apakah Kemiskinan, Pengangguran, Pertumbuhan Ekonomi, dan Belanja Modal berpengaruh terhadap Indeks Pembangunan Manusia (IPM) di Kabupaten Nganjuk. Ada pula tujuan dari dilaksanakannya penelitian ini yaitu untuk mengetahui pengaruh Kemiskinan, Pengangguran, Pertumbuhan Ekonomi dan Belanja Modal terhadap Indeks Pembangunan Manusia (IPM) di kabupaten Nganjuk. Ada pula manfaat dari dilakukan penelitian ini yaitu agar mendapat wawasan serta tambahan informasi ilmu pengetahuan yang memberi manfaat untuk pembaca dan menjadi sebuah referensi bagi bidang keilmuan yang membutuhkan

\section{Metode Penelitian}

Dalam penelitian ini menganalisis secara kuantitatif. Untuk jenis data yang digunakan merupakaniku wes jenis data sekunder dengan sumber data diperoleh dari di BPS (Badan Pusat Statistik) Kabupaten Nganjuk dan Direktorat Jendral Perimbangan Keuangan. Populasi yang ada dalam penelitian ini yaitu seluruh data Kemiskinan,Pengangguran, Pertumbuhan Ekonomi, Dan Belanja Modal Dan Indeks Pembangunan Manusia di Kabupaten Nganjuk. Data diperoleh dengan teknik analisis regresi linier berganda.

\section{Hasil dan Pembahasan}

\section{A. Hasil Penelitian}

\section{Hasil Uji Asumsi Klasik}

\section{a. Uji Autokorelasi}

Berdasarkan hasil dari nilai Durbin Watson sebesar 1,588 dan taraf signifikan 0,05. Untuk nilai $\mathrm{dL}$ sebesar 3,760 lalu nilai $\mathrm{dU}$ sebesar 2,4137. Nilai dari Durbin Watsln tes memperoleh nilai 4-dU $=1,5863$ dan $4-\mathrm{dL}=3,624$ yang berarti berada di daerah keragu-raguan di kedua sisi sehingga diperlukan uji Run Test dengan nilai Asymp. Sig. (2-tailed) sebesar $0,737>$ dari 0,05 yang berarti signifikan, bahwa model tersebut tidak mengalami gejala autokorelasi.

\section{b. Uji Multikolinieritas}

\section{Tabel 1}

Uji Multikolinieritas

\begin{tabular}{cccc}
\hline No & Variabel & VIF & Keterangan \\
\hline 1 & Kemiskinan & 1.426 & Tidak ada Multikolinieritas \\
2 & Pengangguran & 1.971 & Tidak ada Multikolinieritas \\
3 & Pertumbuhan Ekonomi & 1.674 & Tidak ada Multikolinieritas \\
4 & Belanja Modal & 1.085 & Tidak ada Multikolinieritas \\
\hline \multicolumn{4}{c}{ Sumber: Hasil Output SPSS }
\end{tabular}

Bisa dilihat dari tabel 1 Menunjukan bahwa semua variabel independen dari Nilai VIF lebih besar dari 10 sehingga disumpulkan terbebas dari masalah multikolinier secara keseluruhan. 
Pengaruh kemiskinan, pengangguran, pertumbuhan ekonomi, dan belanja modal

\section{c. Uji Heteroskedastisitas}

Berdasarkan hasil uji Spearman's bahwa tingkat signifikan dari variabel Kemiskinan sebesar 1,000, variabel pengangguran sebesar 0.947, variabel pertumbuhan ekonomi sebesar 0.973 dan variabel belanja modal sebesar 0.627 terhadap residual lebih besar dari 0,05 sehingga apat disimpulkan bahwa persamaan ini terbebas dari heteroskedastisitas.

d. Hasil Uji Koefisien Determinasi $\mathbf{R}^{2}$

Dari Hasil nilai $\mathrm{R}^{2}$ sebesar 0,921 dapat disimpulkan bahwa variabel bebas dapat mempengaruhi variabel terikat sebesar 92,1\%. Yang berarti Indeks Pembangunan Manusia (Y) dapat dijelaskan oleh variabel Kemiskinan, Pengangguran, Pertumbuhan Ekonomi,Belanja Modal sebesar $92,1 \%$. Sedangkan $7,9 \%$ dapat menjelaskan variabel lain diluar model persamaan.

e. Hasil Analisis Regresi Linear Berganda

Tabel 2

Hasil Perhitungan Uji Regresi Linier Berganda

\begin{tabular}{llcc}
\hline \multirow{2}{*}{ Model } & \multicolumn{2}{c}{$\begin{array}{c}\text { Unstandardized } \\
\text { Coefficients }\end{array}$} & $\begin{array}{c}\text { Standardized } \\
\text { Coefficients }\end{array}$ \\
\cline { 2 - 4 } & \multicolumn{3}{c}{$\begin{array}{c}\text { Std. } \\
\text { Error }\end{array}$} \\
\hline 1 (Constant) & 6.299 & 0.378 \\
X1= Kemiskinan & -0.341 & 0.063 & -0.816 \\
X2=Pengangguran & -0.003 & 0.016 & -0.036 \\
X3= Pertumbuhan & -0.189 & 0.112 & -0.275 \\
Ekonomi & 0.003 & 0.004 & -0.091 \\
X4= Belanja Modal & & & \\
\hline
\end{tabular}

Sumber: Hasil Output SPSS

Berdasarkan hasil output pada tabel 2 diperoleh Bentuk persamaan regresi yang digunakan dalam penelitian sebagai berikut : IPM $=6,299-0,341$ Kemiskinan- 0,003Pengangguran- $0,189-$ Pertumbuhan Ekonomi- 0,003Belanja Modal

Berdasarkan persamaan diatas maka dapat diketahui bahwa:

1. Nilai koefisien regresi Kemiskinan sebesar $-0,341$ artinya jika Kemiskinan naik 1 persen maka Indeks Pembangunan Manusia akan turun sebesar $0,341 \%$ dengan asumsi variabel bebas yang lain berada di konstan atau sama dengan 0 .

2. Nilai koefisien regresi Pengangguran sebesar -0,003artinya jika Pengangguran naik 1 persen maka Indeks Pembangunan Manusia akan turun sebesar $0,003 \%$ dengan asumsi variabel bebas yang lain berada di konstan atau artinya sama dengan 0 .

3. Nilai koefisien regresi Pertumbuhan Ekonomi sebesar -0.189 artinya jika Pertumbuhan Ekonomi naik 1 persen maka Indeks 
Pembangunan Manusia akan turun $0.189 \%$ dengan asumsi variabel bebas yang lain berada di konstan atau artinya sama dengan 0 .

4. Nilai koefisien regresi Belanja Modal sebesar $-0,003$ artinya jika Belanja Modal naik 1 persen maka Indeks Pembangunan Manusia akan turun 0,003 milyar rupiah dengan asumsi variabel bebas yang lain berada di konstan atau artinya sama dengan 0 .

\section{f. Uji $F$}

Untuk mengetahui besarnya pengaruh dari seluruh variabel bebas secara bersama sama dengan variabel terikat (Sri Desmiarti, 2019). Berikut ini hasil pengujian Uji $\mathrm{F}$ dalam penelitian ini sebagai berikut:

Tabel 3

\section{Hasil ANOVA}

\begin{tabular}{llccccc}
\hline Model & $\begin{array}{c}\text { Sum of } \\
\text { Squares }\end{array}$ & $\begin{array}{c}\text { Mean } \\
\text { Square }\end{array}$ & F & Sig. \\
\hline 1 & Regression & 0.008 & 4 & 0.002 & 14.505 & $0.006^{\mathrm{b}}$ \\
Residual & 0.001 & 5 & 0.000 & & \\
Total & 0.008 & 9 & & & \\
\hline \multicolumn{6}{c}{ Sumber: Hasil Output SPSS } \\
\end{tabular}

Berdasarkan tabel 3 mengenai uji $\mathrm{F}$ yang bertujuan untuk mengetahui secara simultan mengenai pengaruh kemiskinan,pengangguran,belanja

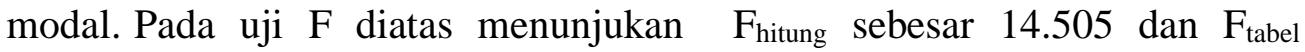
sebesar 5,19. Dengan demikian Fhitung > Ftabel dan signifikan sebesar $0.006<0,05$. Maka dapat disimpulkan bahwa Kemiskinan, Pengangguran, Pertumbuhan Ekonomi, Belanja modal, memiliki pengaruh signifikan secara simultan terhadap Indeks Pembangunan Manusia (IPM).

\section{g. Uji t}

Uji T digunakan untuk mengetahui besar tidaknya signifikan suatu variabel independent terhadap variabel dependent secara individu dan variabel lain bersifat konstanta (RAHAYU, 2019). Berikut ini hasil dari uji t sebagai berikut.

Tabel 4

Hasil Uji $t$

\begin{tabular}{lrrrrrr}
\hline & \multicolumn{2}{c}{$\begin{array}{c}\text { Unstandardized } \\
\text { Coefficients }\end{array}$} & \multicolumn{2}{c}{$\begin{array}{c}\text { Standardized } \\
\text { Coefficients }\end{array}$} & & \\
\cline { 2 - 5 } Model & $\mathrm{B}$ & Std. & Error & Beta & \multicolumn{1}{c}{ t } & \multicolumn{1}{c}{ Sig. } \\
\hline 1 1.Constant $)$ & 6.299 & .378 & & 16.645 & .000 \\
\hline Kemiskinan & -.341 & .063 & -.816 & -5.423 & .003 \\
\hline Pengangguran & -.003 & .016 & -.036 & -.204 & .847 \\
\hline $\begin{array}{l}\text { Pertumbuhan } \\
\text { Ekonomi }\end{array}$ & -.189 & .112 & -.275 & -1.686 & .153 \\
\hline Belanja Modal & -.003 & .004 & -.091 & -.695 & .518 \\
\hline
\end{tabular}

Sumber: Hasil Output SPSS 
Berdasarkan tabel 3 Pengujian ini menggunakan uji dua sisi dan tingkat signifikan sebesar 0,05. Berikut ini hasil pengujian Uji $t$ dengan bantuan program SPSS antara lain:

1) Pada variabel $X_{1}$ Kemiskinan diperoleh $t_{\text {hitung }}-5,423>t_{\text {tabel }} 2,57058$ yang artinya $\mathrm{H}_{0}$ ditolak dan $\mathrm{H}_{1}$ diterima. Ini berarti secara parsial Kemiskinan $\left(\mathrm{X}_{1}\right)$ berpengaruh signifikan dan berhubungan negatif terhadap Indeks Pembangunan Manusia (Y).

2) Pada variabel $X_{2}$ Pengangguran diperoleh $t_{\text {hitung }}-0,204<t_{\text {tabel }} 2,57058$ yang artinya $\mathrm{H}_{0}$ diterima dan $\mathrm{H}_{1}$ ditolak. Ini berarti secara parsial Pengangguran $\left(\mathrm{X}_{2}\right)$ tidak berpengaruh signifikan dan berhubungan negatif terhadap Indeks Pembangunan Manusia (Y).

3) Pada variabel $X_{3}$ Pertumbuhan Ekonomi diperoleh $t_{\text {hitung }}-1,686<t_{\text {tabel }}$ 2,57058 yang artinya $\mathrm{H}_{0}$ diterima dan $\mathrm{H}_{1}$ ditolak. Ini berarti secara parsial Pertumbuhan Ekonomi $\left(\mathrm{X}_{3}\right)$ tidak berpengaruh signifikan dan berhubungan negatif terhadap Indeks Pembangunan Manusia (Y).

4) Pada variabel $X_{4}$ Belanja Modal diperoleh $t_{\text {hitung }}-0,695<t_{\text {tabel }} 2,57058$ yang artinya $\mathrm{H}_{0}$ diterima dan $\mathrm{H}_{1}$ ditolak. Ini berarti secara parsial Belanja Modal $\left(\mathrm{X}_{4}\right)$ tidak berpengaruh signifikan dan berhubungan negatif terhadap Indeks Pembangunan Manusia (Y).

\section{B. Pembahasan}

\section{Pengaruh Kemiskinan Terhadap Indeks Pembangunan Manusia}

Berdasarkan hasil analisis yang sudah dilakukan menunjukkan bahwa kemiskinan berpengaruh negative dan signifikan terhadap indeks pembangunan manusia di Kabupaten Nganjuk. Hal ini artinya bahwa semakin banyak masyarakat yang sadar pentingnya kualitas pendidikan sehingga meningkatnya kualitas sumber daya manusia maka produktivitas tenaga kerja juga akan naik dan pendapatan ikut naik pula lalu tingkat kemiskinan akan turun. Hal ini sesuai dengan penelitian yang dilakukan oleh (Mirza, i2012) menyatakan bahwa kemiskinan memiliki pengaruh signifikan terhadap indeks pembangunan manusia.

\section{Pengaruh Pengangguran Terhadap Indeks Pembangunan Manusia}

Berdasarkan hasil analisis yang sudah dilakukan menunjukkan bahwa pengangguran tidak memiliki pengaruh terhadap indeks pembangunan manusia di Kabupaten Nganjuk. Hal ini disebabkan oleh banyaknya pengangguran yang merupakan golongan angkatan kerja yang merasa tidak sesuai dengan pekerjaan yang telah dijalani sehingga mencari pekerjaan yang lebih baik, sesuai skill sehingga tingkat pengangguran turun dan terjadi pemerataan pendapatan yang mendorong meningkatnya indeks pembangunan manusia. Hasil ini bertentangan dengan penelitian yang dilakukan oleh (Baeti,2013) bahwa pengangguran tidak berpengaruh negatif dan signifikan terhadap Indeks Pembangunan Manusia di Provinsi Jawa Tengah. 


\section{Pertumbuhan iEkonomi iTerhadap iIndeks iPembangunan iManusia}

Berdasarkan hasil analisis yang sudah dilakukan menunjukkan bahwa pertumbuhan ekonomi tidak berpengaruh terhadap Indeks Pembangunan Manusia di Kabupaten Nganjuk. Hal ini menujukkan jika pertumbuhan ekonomi menurun sehingga produksi barang dan jasa ikut turun lalu produsen tidak bisa menghasilkan barang yang murah sehingga menurunkan kualitas standart hidup manusia yang mengakibatkan kesejahteraan masyarakat ikut turun menyebabkan IPM mengalami penurunan pula (Dewi, Yusuf, \& Iyan, 2016). Hasil penelitian ini tidak sesuai dengan penelitian yang dilakukan (Salem, 2018) yang menyatakan bahwa adanya pengaruh antara pertumbuhan ekonomi terhadap IPM di Provinsi NTT.

\section{Pengaruh Belanja Modal Terhadap Indeks Pembangunan Manusia}

Berdasarkan hasil analisis yang sudah dilakukan menunjukkan bahwa belanja modal tidak berpengaruh terhadap indeks pembangunan manusia di Kabupaten Nganjuk. Untuk nilai belanja di Kabupaten Nganjuk ini memiliki trend yang tidak stabil setiap tahunnya. Menurut (Komariah iet ial., i2019) Hal ini melihatkan kondisi yang fluktuasi sehingga hal ini berdampak terhadap menurunnya kualitas ketersediaan pelayanan publik terutama pada sektor pendidikan, kesehatan serta ekonomi agar pemerintah dapat meningkatkan pencapaian pembangunan manusia. Hasil ini tidak sejalan dengan penelitian dari (Zakaria, 2018) menyatakan bahwa belanja modal berpengaruh signifikan terhadap IPM di Provinsi Jawa Tengah.

\section{Kesimpulan}

Dari hasil pengujian hipotesa dengan menggunakan analisis regresi linier berganda, maka bisa diambil kesimpulan sebagai berikut: Pertama, Variabel Kemiskinan berpengaruh negative secara signifikan terhadap Indeks Pembangunan Manusia di Kabupaten Nganjuk. Kedua, Variabel Pengangguran tidak berpengaruh secara signifikan terhadap Indeks Pembangunan Manusia di Kabupaten Nganjuk. Ketiga, Variabel Pertumbuhan Ekonomi tidak berpengaruh secara signifikan terhadap Indeks Pembangunan Manusia di Kabupaten Nganjuk. Keempat, Variabel Belanja Modal tidak berpengaruh secara signifikan terhadap Indeks Pembangunan Manusia di Kabupaten Nganjuk. 
Pengaruh kemiskinan, pengangguran, pertumbuhan ekonomi, dan belanja modal

\section{BIBLIOGRAFI}

Adi, Priyo Hari. (2006). Hubungan antara pertumbuhan ekonomi daerah, belanja pembangunan dan pendapatan asli daerah. Simposium Nasional Akuntansi IX, 2326.Google Scholar

Badan Pusat Statistik Nganjuk. (2020a). Data Kemiskinan Tahun 2010-2019.

Badan Pusat Statistik Nganjuk. (2020b). Nilai IPM tahun 2010-2019.

Baeti, Nur. (2013). Pengaruh Pengangguran, Pertumbuhan Ekonomi, Dan Pengeluaran Pemerintah Terhadap Pembangunan Manusia Kabupaten/Kota Di Provinsi Jawa Tengah Tahun 2007-2011. Economics Development Analysis Journal, 2(3), 85-98.

Bappeda. (2020a). Pengertian Pengangguran. Retrieved from https://bappeda.nganjukkab.go.id/

Bappeda. (2020b). Pengertian Pertumbuhan Ekonomi. Retrieved from https://bappeda.nganjukkab.go.id/

Dewi, N., Yusuf, Y., \& Iyan, R. (2016). Pengaruh Kemiskinan Dan Pertumbuhan Ekonomi Terhadap Indeks Pembangunan Manusia Di Provinsi Riau. Jurnal Online Mahasiswa Fakultas Ekonomi Universitas Riau, 4(1), 870-882.Google Scholar

Komariah, Diah, Yogiantoro, Mukhammad, \& Hukom, Alexandra. (2019). Penagaruh Belanja Modal dan Pertumbuhan Ekonomi terhadap Indeks Pembangunan Manusia. Jurnal Riset Manajemen Dan Bisnis Fakultas Ekonomi UNIAT, 4(S1), 523-532. Google Scholar

Mirza, Deni Susilo. (2012). Pengaruh Pertumbuhan Ekonomi Terhadap IPM. Jurnal Ekonomi Pembangunan, 1(1), 8.

Mirza, Denni Sulistio. (2012). Pengaruh kemiskinan, pertumbuhan ekonomi, dan belanja modal terhadap indeks pembangunan manusia di Jawa Tengah tahun 20062009. Economics Development Analysis Journal, 1(2). Google Scholar

Prakosa, Kesit Bambang. (2004). Analisis pengaruh dana alokasi umum (DAU) dan pendapatan asli daerah (PAD) terhadap prediksi belanja daerah (studi empirik di wilayah propinsi Jawa Tengah dan DIY). Jurnal Akuntansi Dan Auditing Indonesia, 8(2).

Rahayu, Nia Aditia. (2019). Pengaruh Kemiskinan Dan Pertumbuhan Ekonomi Terhadap Indeks Pembangunan Manusia (Ipm) Dalam Persepektif Ekonomi Islam Di Kabupaten Lampung Tengah Tahun 2010-2017 (Vol. 8). Google Scholar

Salem, Thomas Aquinas. (2018). Pengaruh Pertumbuhan Ekonomi Daerah, Belanja Daerah, Dan Tingkat Kemiskinan Terhadap Indeks Pmebangunan Manusia (IPM) Di Provinsi NTT Periode 2001-2016. 
Sri Desmiarti. (2019). Pengaruh Pdrb Dan Tingkat Pengangguran Terbuka Terhadap Indeks Pembangunan Manusia Di Kabupaten Langkat. Google Scholar

Zakaria, Rizaldi. (2018). Pengaruh Tingkat Jumlah Penduduk, Pengangguran, Kemiskinan, Pertumbuhan Ekonomi Dan Belanja Modal Terhadap Indeks Pembangunan Manusia Di Provinsi Jawa Tengah Tahun 2010-2016. Dspace UII. Google Scholar

\section{Copyright holder :}

Andhita Astriani, Muchtolifah, Sishadiyati (2021)

\section{First publication right :}

Syntax Idea

This article is licensed under:

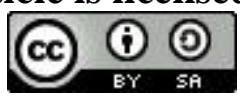

